\title{
Influence of the aggregate quality on the physical properties of natural feebly-hydraulic lime mortars
}

\author{
S. Pavía $\cdot$ B. Toomey
}

Received: 18 July 2006/ Accepted: 16 May 2007

(C) RILEM 2007

\begin{abstract}
This paper examines the influence of the shape, average size and calcite content of the aggregate on strength, porosity, water absorption, density and capillary suction of natural feeblyhydraulic lime (NHL 2) mortars. Four types of aggregate were analysed in order to determine calcite content, particle shape and average particle size. Four different mortar mixes were then designed and produced using each of the aggregate types and NHL 2 as a binder. The mixing and curing as well as the aggregate:binder proportions were kept constant in order to attribute variation of mortar properties to the quality of the aggregate. The results suggest that an increase in the aggregate's calcite content lowers the flexural and compressive strength of the mortar. This study also determined that sharp aggregate as well as aggregate with a small average particle size tends to increase the mechanical strength and bulk density of a mortar simultaneously reducing porosity, water absorption and capillary suction. Furthermore, this paper concludes that aggregates containing particles of a wide size range will also increase the mechanical strength and bulk density of the hardened mortar diminishing porosity, water absorption and capillary suction.
\end{abstract}

S. Pavía $(\varangle) \cdot$ B. Toomey

Department of Civil, Structural and Environmental Engineering, Trinity College Dublin, Dublin 2, Ireland e-mail: pavias@tcd.ie
Résumé Cet article étudie l'influence de la forme, de la taille moyenne, de la proportion en calcite des granulats sur la résistance, la porosité, l'absorption d'eau globale, l'absorption d'eau par capillarité et la densité de mortiers de chaux naturelle faiblement hydraulique (NHL 2). Quatre types de granulats ont été analysés en vue de déterminer leur teneur en calcite ainsi que la forme et la taille moyenne de leurs particules. Quatre mortiers différents ont été ensuite conçus et gâchés en utilisant chaque type de granulats et la chaux NHL 2 comme liant. Le temps de malaxage, les conditions de séchage et la proportion granulats:liant sont restés identiques au cours des différents essais de façon à attribuer à la seule qualité des granulats les différences de propriétés du mortier observées. Les résultats suggèrent qu'une augmentation de la teneur en calcite des granulats diminue la résistance en compression et en flexion du mortier. Cette étude établit aussi que des granulats anguleux, comme des granulats avec une taille moyenne de particule faible, ont tendance à augmenter la résistance mécanique et la masse volumique apparente d'un mortier réduisant simultanément sa porosité, son absorption d'eau globale et son absorption d'eau par capillarité. De plus, cet article conclut que des granulats contenant des particules à granulométrie étalée auront aussi tendance à augmenter la résistance mécanique et la masse volumique apparente du mortier durci diminuant sa porosité, son absorption d'eau globale et son absorption d'eau par capillarité. 
Keywords Natural feebly-hydraulic lime . Aggregate's shape - Size and calcite content . Mortar strength · Porosity · Absorption .

Density $\cdot$ Suction

Mots clé Chaux naturelle faiblement hydraulique . Forme - Taille et teneur en calcite des granulats . Résistance du mortier · Porosité .

Absorption - Masse volumique . Capillarité

\section{Introduction}

The fact that aggregate quality influences the properties of lime mortar and concrete has been known since, at least, the Roman times. It is evident from the classic authors that the Romans preferred sharp sands to rounded sands, as they knew that these would produce stronger mortars. For example, Palladius [1] refers to the higher quality of sharp sand as follows: 'those (sands) that remain together after you pressing them in your fist are good for building'. Pliny The Elder [2] agrees with this, advising to strengthen weak rounded aggregate by adding pozzolans and varying the aggregate/binder ratio as follows: 'of sand, there are three varieties: there is a quarry sand, to which has to be added one-quarter of its weight in lime; and river or alternatively sea sand, to which must be added onethird. If one-third of crushed potsherds is also added, the material will be improved'. Vitruvius agrees with the above remarking that river sands are too tenuous to make proper concrete and, in order to strengthen them, they need to be mixed with pozzolans [3]. Furthermore, Vitruvius, Palladius and Flaventinus recommend the use of 'pit (quarry) sand' for load bearing walls 'as it sets easily', insisting that it must have no earthiness (as tested by the sound it makes between one's fingers and its failure to stain a white cloth) [4]. This reference to the lack of 'earthiness' evidences that the Romans were aware of aggregate failure due to contamination with clay and silt particles, and that they were prepared to avoid it by correctly selecting the aggregate. The classic authors were also aware of mortar failure due to salt-contaminated aggregate. For example, Vitruvius, Palladius and Flaventinus attributed slow setting and structural weakness of mortars to the use of sea sand [4]: 'sand of this type (sea-sand) has the drawback that it takes a long time to dry so that one can build up only at intervals, while it will never support a vault'... 'the sand in concrete made from sea sand will dissolve any coat of stucco applied to it'. In addition, Vitruvius [3] states that, where pit sand was lacking, sand from river beds or gravel beds or even sea-shore sand was to be used. However, Palladius [1] remarks that if we have no choice but using sea sand, we need to wash it before use, keeping it immersed in water to eliminate the salt.

A number of authors have later studied the influence of aggregate composition on lime mortars. For example, following a number of experiments, Vicat reported in 1837 [5] that calcareous sand consistently produced stronger mortars than noncalcareous sand, however he also states that the difference in strength was always minor. Lanas et al. [6] agrees with the above, stating that the strength of a mortar increases by using a limestone aggregate due to the syntaxial growth of calcite leading to an enhanced binder/aggregate interface. However, Holmes et al. [7] disagree with this, claiming that limestone aggregate produces a softer mortar.

It is generally accepted that the strongest mixes are produced from well graded, clean and sharp aggregate. For example, Cowper [8] states that sharp sand (i.e. pit sand) should be preferred to a more rounded one (i.e. river sand) in order to induce maximum mechanical strength agreeing with Holmes et al. [7] as well as the Roman authors above. Lanas et al. [9] also agree with this, evidencing through testing that angular aggregate increases mechanical strength. It is also generally accepted that aggregate grading significantly affects mortar properties. For example, according to St Astier [10], monogranular sands diminish mortar workability, and there are specific aggregate particle size distributions adequate for particular mortars. In addition, Pavía et al. [11] state that mortar porosity and, subsequently, strength gain over time are determined by the aggregate's packing which in turn is determined by the grading, and that the tighter the aggregate packing the lower the mortar porosity. These authors also suggest that, in order to obtain the tightest packing and, subsequently, a stronger mortar, sharp, well-graded sand including a wide range of particle sizes should be used. Lanas et al. [9] agree with this, claiming that a suitable grain size distribution allows higher mortar strengths. These authors demonstrate that an increase in porosity reduces the strength of a mortar however, they claim that this is only true when the binder is in 
excess and that, when the binder is not in excess, an increase in porosity enhances carbonation thus enhancing strength. Allen et al. [12] agree with the above, stating that a too great a concentration of one or two particle sizes in hydraulic lime mortars results in a poor packing thus reducing workability therefore requiring additional water which adversely affects strength. These authors also remark that, for a specific workability, water content may be lowered by increasing the aggregate particle size thus enhancing mortar strength. In relation to the aggregate size, there are discrepancies on whether a coarser or a finer average particle size would optimise mortars properties. According to Lanas et al. [6] mortar strength increases with the use of a small grain sized aggregate and decreases with the use of rounded aggregate as the latter enhances mortar's porosity. Finally, Stefanidou et al. [13] studied the effect of particle size distribution, compaction and binder/ aggregate ratio on capillary suction, strength development and volume change of air lime mortar, concluding that both water absorption and capillary suction increase with increasing grain size, and that the mortars with the highest strength values were those prepared with aggregate particles ranging between 0 and $4 \mathrm{~mm}$.

According to the above, while it seems generally accepted that the strongest mixes are produced from well graded, clean and sharp aggregate, there are discrepancies on whether calcareous aggregate produces stronger mortars than siliceous aggregate and whether a coarser or a finer average particle size would enhance mortar properties. In order to provide further evidence on these, this paper studies the influence of aggregate shape, average size and calcite content on the mechanical strength, porosity, water absorption, density and capillary suction of natural feebly-hydraulic lime mortars through laboratory testing. The mechanical strength of a lime mortar depends on a great number of factors including curing time, binder: aggregate and binder: water ratios, nature, shape and grading of aggregate and compaction. On the mortars tested, most of these factors were kept constant in order to attribute variation in mortar properties to the aggregate quality. Properties including porosity, water absorption, density and capillary suction were measured because they control the presence and movement of moisture in the mortar thus regulating processes such as strength development over time as well as salt and frost damage and water dissolution, which are responsible for mortar weathering [11].

\section{Materials and methods}

\subsection{Aggregate grading}

The grain size and particle size distribution were determined in accordance with European standards [14]. The aggregate mass retained by each sieve was calculated as a percentage of the original dry mass. In addition, the percentage of fines was calculated according to the equation below:

$\mathrm{f}=\frac{\left(\mathrm{M}_{1}-\mathrm{M}_{2}\right)+\mathrm{P}}{\mathrm{M}_{1}}$

where

$\mathrm{f}$ is the $\%$ fines of initial dry mass (\%),

$\mathrm{M}_{1}$ the initial dry mass $(\mathrm{g})$,

$\mathrm{M}_{2}$ the dry mass of the residue after washing (g),

$\mathrm{P}$ is the mass of the screened material remaining in the pan $(\mathrm{g})$.

The cumulative $\%$ of the original dry mass passing each sieve was plotted vs. the log of each sieve size therefore determining the average particle size of each aggregate.

\subsection{Grain morphology and composition}

The shape, sphericity and roundness of the aggregates were determined with a scanning electron microscope (SEM). The analytical system employed was a Zeiss DSM-950 SEM equipped with a backscattered electron detector and a LINK-QX 2000 energy dispersive X-ray analysis attachment (EDX). Spectrums were taken with a voltage of $20 \mathrm{kV}$ through a beryllium window. The system provided high-resolution, three-dimensional images of the aggregate as well as qualitative elemental analyses of specific grains. The aggregate composition was also analysed with a petrographic microscope using both polarised and natural light and objectives of $2 \times, 10 \times, 20 \times$ and $40 \times$ magnification. Four different aggregates were used (Table 1). Particle size distribution, morphology and composition are included in results. The aggregates were embedded in a resin and thin sectioned. In order to verify that there 
Table 1 Details of the aggregates tested

\begin{tabular}{ll}
\hline Notation & Details \\
\hline StA & $\begin{array}{c}\text { Natural, regarded as high quality aggregate, often } \\
\text { prescribed for conservation works to masonry }\end{array}$ \\
Red 5 & Natural sandstone aggregate \\
Ls & Manufactured limestone aggregate \\
Mor & Natural aggregate from a granite-bedrock area \\
\hline
\end{tabular}

was no significant dolomite content in the aggregate, the aggregate was dyed with a chemical solution containing alizarin and potassium ferrocyanide. This made it possible to distinguish, under the microscope, the different carbonate minerals present in the mortars e.g. calcite and dolomite.

The carbonate content was analysed by reaction with hydrochloric acid as shown in the equation below:

$$
\mathrm{CaCO}_{3}+\mathrm{HCl} \longrightarrow \mathrm{CaCl}_{2}+\mathrm{CO}_{2}+\mathrm{H}_{2} \mathrm{O}
$$

Here, change in mass is due to evaporation of $\mathrm{CO}_{2}$. Provided that $\mathrm{CaCO}_{3}$ is the limiting reactant and the reaction is fully completed, for every $44 \mathrm{~g}$ of mass loss during the reaction $100 \mathrm{~g}$ of $\mathrm{CaCO}_{3}$ are present (atomic masses of $\mathrm{CaCO}_{3}$ and $\mathrm{CO}_{2}$ are 100 and 44 respectively). Therefore, the $\mathrm{CaCO}_{3}$ content of the aggregate was calculated according to the formula below:

$$
\begin{aligned}
& \mathrm{M}_{\mathrm{CO}_{2}}=\mathrm{M}_{\mathrm{i}}-\mathrm{M}_{\mathrm{f}} \\
& \mathrm{M}_{\mathrm{CaCO}_{3}}=\frac{\mathrm{M}_{\mathrm{CO}_{2}} \times 100}{44} \\
& \mathrm{~L}=\frac{\mathrm{M}_{\mathrm{caco}_{3}}}{25}
\end{aligned}
$$

where

$$
\begin{aligned}
& \mathrm{M}_{\mathrm{i}} \text { is the initial mass }(\mathrm{g}) \text {, } \\
& \mathrm{M}_{\mathrm{f}} \text { the final mass }(\mathrm{g}) \text {, } \\
& \mathrm{M}_{\mathrm{CO}_{2}} \text { the mass of } \mathrm{CO}_{2} \text { lost }(\mathrm{g}) \text {, } \\
& \mathrm{M}_{\mathrm{CaCO}_{3}} \text { themass of } \mathrm{CaCO}_{3} \text { in aggregate }(\mathrm{g}) \text {, } \\
& \mathrm{L} \text { is the } \mathrm{CaCO}_{3} \text { content of aggregate }(\%) \text {. }
\end{aligned}
$$

\subsection{Sulphate content of aggregate}

The sulphate content of the aggregates was measured photometrically with a spectrophotometer in order to assess possible salt contamination that could adversely affect the final results of the mortar properties measured.

\subsection{Mixing, initial flow and curing}

The aggregate to binder ratio was $3: 1$. The standards state that a water/binder ratio of 0.55 should be used when mixing NHL 2 mortars [15, 16]; however, mortars including different aggregate should require different volumes of water depending on aggregate properties such as porosity and specific surface. Therefore, in order to ensure that all mortars included the correct amount of water that would ensure a good workability and final quality, it was decided to add the amount needed in each case in order to keep workability, as measured by the initial flow, constant. The flow test was conducted in accordance with European standards [15]. The workability was kept constant by ensuring that all mortars had an initial flow diameter of $165 \pm 3 \mathrm{~mm}$ [17]. The water content to reach this flow was in the range of $17 \%$ by weight. The mortars were moulded, compacted on a vibration table according to [15], and removed from the moulds after 2 days. They were initially covered with damp towels to prevent shrinkage cracking and cured for 56 days in order to allow carbonation, in conditions of approximately $60 \%$ humidity and $17-20^{\circ} \mathrm{C}$ temperature. Each property was measured in three samples of every mortar, and the arithmetic mean of the results calculated.

\subsection{Flexural strength}

Flexural strength dictates the strength of the mortar in bending (e.g. the maximum lateral load that a wall may take) being therefore an essential figure for building designers. This property was tested according to EN 459-2 [15]. However, the load was applied manually, at a rate of $20 \pm 5 \mathrm{~N} / \mathrm{s}$ with a steady rate of strain. The specimens were placed on the support rollers with their longitudinal axis normal to the supports. The load was applied vertically by means of a loading roller on the opposite side of the supports until fracture occurred. The flexural strength was measured at the surface of the specimen on the convex (tension) side according to the formula below:

$\mathrm{R}_{\mathrm{f}}=\frac{1.5 \times \mathrm{F}_{\mathrm{f}} \times 1}{\mathrm{~b}^{3}}$ 
where

$R_{f}$ is the flexural strength $\left(\mathrm{N} / \mathrm{mm}^{2}\right)$,

$\mathrm{b}$ is the length of the side of the square section (mm),

$\mathrm{F}_{\mathrm{f}}$ is the load applied at fracture $(\mathrm{N})$,

1 is the distance between the two supports (mm)$(100 \mathrm{~mm})$.

\subsection{Compressive strength}

The compressive strength of a mortar is the maximum compressive load which may be applied to the mortar per a unit area before failure occurs. This property was tested according to EN 459-2 [15]. As for flexural strength, the samples were placed in a curing tank for 5 days and removed 15 min prior to testing. The load was applied at a rate of $40 \pm 10 \mathrm{~N} / \mathrm{s}$ until failure occurred. The compressive strength was calculated according to the equation below:

$\mathrm{R}_{\mathrm{c}}=\mathrm{F}_{\mathrm{c}} / \mathrm{A}$

where

$\mathrm{R}_{\mathrm{c}}$ the compressive strength (MPa),

$\mathrm{A}$ is the area of applied load $\left(\mathrm{mm}^{2}\right)$,

$\mathrm{F}_{\mathrm{c}}$ the load applied at failure $(\mathrm{N})$.

\subsection{Porosity}

The porosity of a mortar is the ratio of the volume of voids to the volume of solid material. It was tested according to RILEM recommendations [18]. The samples were dried till constant weight $\left(\mathrm{M}_{d}\right)$. They were placed in an evacuation vessel and the pressure gradually lowered and kept constant for $24 \mathrm{~h}$. The saturated samples were weighed at atmospheric pressure and the hydrostatic mass measured. The porosity was calculated according to the equation below:

$\mathrm{P}=\frac{\mathrm{M}_{\mathrm{s}}-\mathrm{M}_{\mathrm{d}}}{\mathrm{M}_{\mathrm{s}}-\mathrm{M}_{\mathrm{h}}} \times 100$

where

$\mathrm{M}_{\mathrm{d}}$ the dry mass $(\mathrm{g})$,

$\mathrm{M}_{\mathrm{h}}$ the hydrostatic mass (g),

$\mathrm{M}_{\mathrm{s}}$ the saturated mass $(\mathrm{g})$,
$\mathrm{P}$ is the porosity accessible to water (\%).

\subsection{Water absorption}

The water absorption is the ratio of the mass of water a mortar can retain to the dry mass of the mortar and was measured according to UNE [19]. The samples were immersed for $48 \mathrm{~h}$ at atmospheric pressure and the property calculated according to the equation below:

$\mathrm{WA}=\frac{\mathrm{M}_{\mathrm{s}}-\mathrm{M}_{\mathrm{d}}}{\mathrm{M}_{\mathrm{d}}} \times 100$

where

$\mathrm{M}_{\mathrm{d}}$ the dry mass (g),

$\mathrm{M}_{\mathrm{s}}$ the saturated mass $(\mathrm{g})$,

WA is the water absorption (\%).

\subsection{Bulk density}

The bulk density is the ratio of the mass of the mortar to its bulk volume. It was measured according to RILEM recommendations [18]. This value is required for calculating the self-weight of a mortar structure and may also be used as an indicator of porosity. The bulk density (B $-\mathrm{Kg} / \mathrm{m}^{3}$ ) was calculated according to the equation below:

$\mathrm{B}=\frac{\mathrm{M}_{\mathrm{d}}}{\mathrm{M}_{\mathrm{s}}-\mathrm{M}_{\mathrm{h}}} \times 10^{3}$

\subsection{Capillary suction}

Capillary suction is the process by which moisture travels through fine pores due to tension forces developed between the solid particles and the water molecules. Capillary suction was measured according to the relevant standards [20]. The dry samples were immersed to a depth of $3 \pm 1 \mathrm{~mm}$. They were removed and weighed at specific time intervals of 1 , $3,5,15,30$ and $60 \mathrm{~min}$. The coefficient of water absorption by capillarity $\left(\mathrm{C}\left(\mathrm{g} / \mathrm{m}^{2} \mathrm{~s}^{0.5}\right)\right)$ was calculated by plotting the ratio $\mathrm{M}_{\mathrm{i}}-\mathrm{M}_{\mathrm{d}} / \mathrm{A}$ versus $\sqrt{ } \mathrm{t}_{\mathrm{i}} \cdot$ where: 
$M_{i}=$ weight of sample after a specific time interval $\mathrm{t}_{i}(\mathrm{~g})$.

$\mathrm{M}_{\mathrm{d}}=$ dry weight $(\mathrm{g})$.

$\mathrm{A}=$ area of immersed base $\left(\mathrm{m}^{2}\right)$.

$\mathrm{t}_{\mathrm{i}}=$ immersion time $(\mathrm{s})$.

The slope for each function was calculated and the arithmetic mean of the three values taken as the coefficient of water absorption by capillarity of the mortar.

\section{Results}

\subsection{Particle size distribution, aggregate morphology and composition}

The analysis of particle size distribution in Fig. 1 suggests that the Mor sand possesses the largest average particle size while the StA and Red 5 are the 2nd and 3rd coarsest respectively, and the Limestone sand contains the smallest average particle size. In addition, on view of the accumulative curves in Fig. 2 and according to BS 1200:1976 [21], the Red 5 sand shows the best grading, while the Limestone and St A sands were equally well-graded and the Mor sand possesses the worst grading, including a significant silt and clay fraction (particles sized under $75 \mu \mathrm{m}$ ). The aggregate mineralogy and grain morphology based on petrographic and SEM analysis are included in Table 2 and Figs. 3-10. With regard to grain morphology, the StA and Red 5 are the sharpest aggregates followed by the limestone sand (Ls)

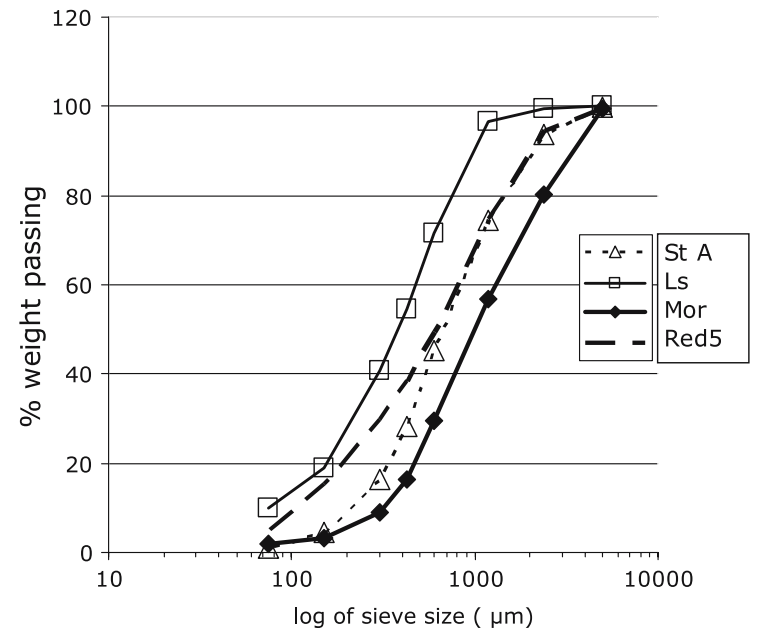

Fig. 2 Accumulative curves of aggregate's particle size

while the Mor sand contains a mix of both angular and rounded particles. Most of the aggregates contain particles of low to medium sphericity except for the Mor sand which includes both high and low sphericity particles. According to the hydrochloric acid digestion results, the Limestone sand had an extremely high $\mathrm{CaCO}_{3}$ content (84\%) followed by the Mor sand $(15 \%)$ while the StA sand included $4.8 \%$ and the Red 5 contained no calcite. The results from petrographic analysis agree with the above except for the StA sand, where no calcite was determined through petrographic analysis. No dolomite was determined in the aggregates with petrographic analysis. In addition, no sulphate contamination was detected photometrically. This agrees with the analytical
Fig. 1 Particle size distribution of aggregates. Mesh size of sieves in $\mu \mathrm{m}$ : $1=5,000 ; 2=2,360$;

$3=1,180 ; 4=600 ; 5=425$; $6=300 ; 7=150 ; 8=75$;

$9=\operatorname{pan}$

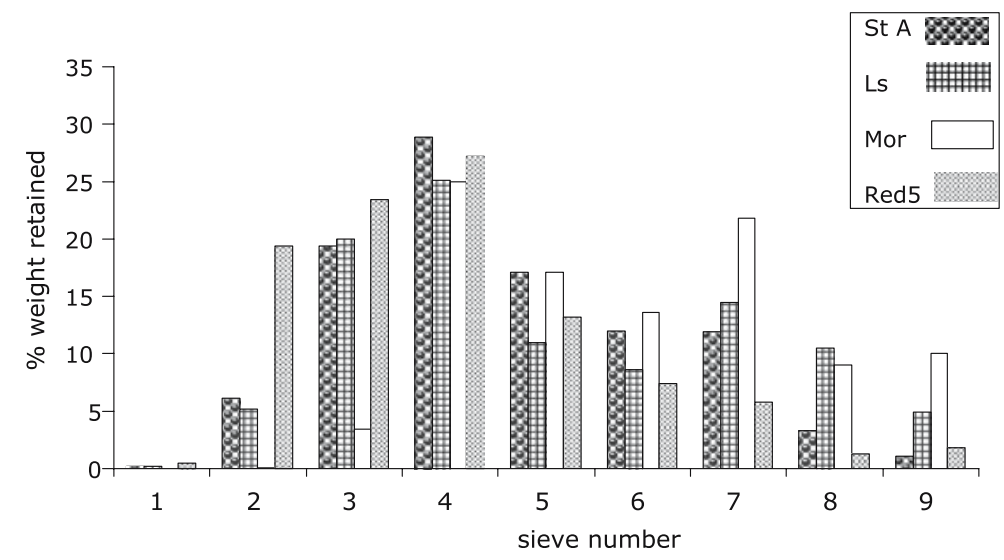


Table 2 Aggregate mineralogy and grain morphology based on petrographic and SEM analyses (Figs. 3-10)

\begin{tabular}{|c|c|c|c|c|}
\hline \multirow[t]{2}{*}{ Notation } & \multicolumn{2}{|l|}{ Mineralogy } & \multicolumn{2}{|l|}{ Grain morphology } \\
\hline & Main & Minor & Sphericity & Roundness \\
\hline StA & Quartz & Feldspar chert opaques & Low/medium & Very angular \\
\hline Red 5 & $\begin{array}{l}\text { Sandstone (siliceous and } \\
\text { argillaceous) }\end{array}$ & Quartz feldspar rock-fragments & Low/medium & Very angular \\
\hline Ls & Calcite & Quartz & Low/medium & Angular \\
\hline Mor & Quartz Ca-limestone chert & $\begin{array}{l}\text { Feldspar shale sandstone granite } \\
\text { metamorphic-rocks }\end{array}$ & $\begin{array}{l}\text { Variable(high and } \\
\text { low) }\end{array}$ & $\begin{array}{l}\text { Angular to } \\
\text { rounded }\end{array}$ \\
\hline
\end{tabular}

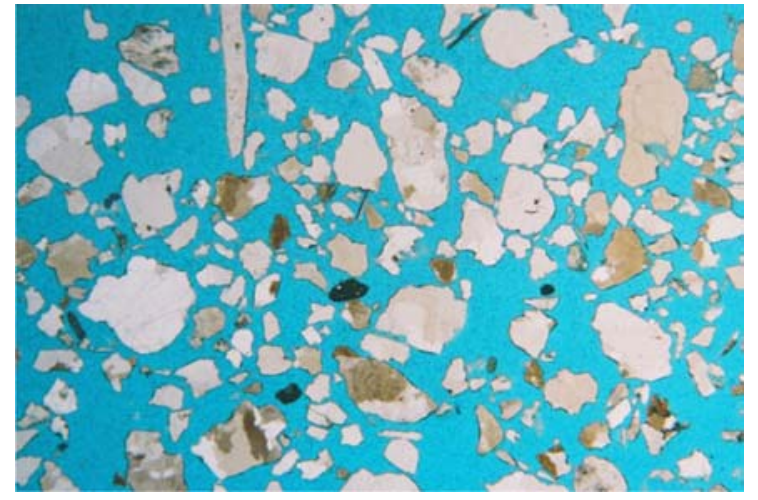

Fig. 3 Optical micrograph of thin section of StA aggregate consisting of mainly quartz with lower amounts of feldspar and chert and occasional amorphous silica. $2 \times$ polarised light

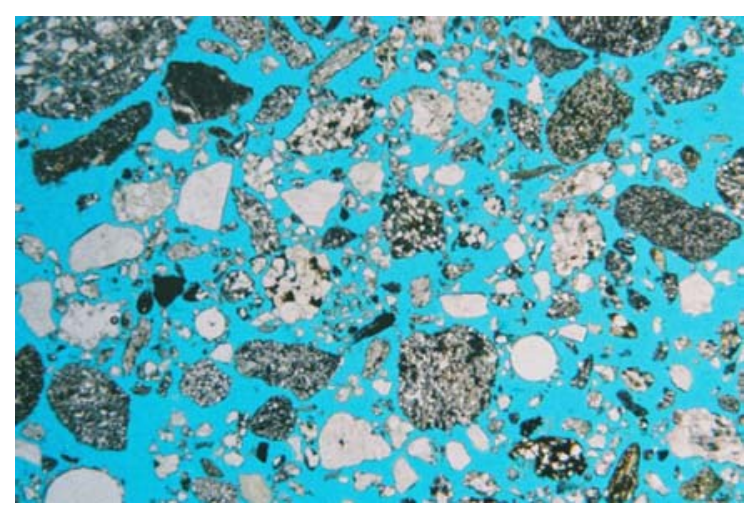

Fig. 4 Optical micrograph of thin section of Red 5 aggregate containing sandstone and occasional quartz, feldspar and rock fragments. $2 \times$ natural light

results by EDXA which evidenced neither sulphur nor other elements capable of acting as anions while forming salts.

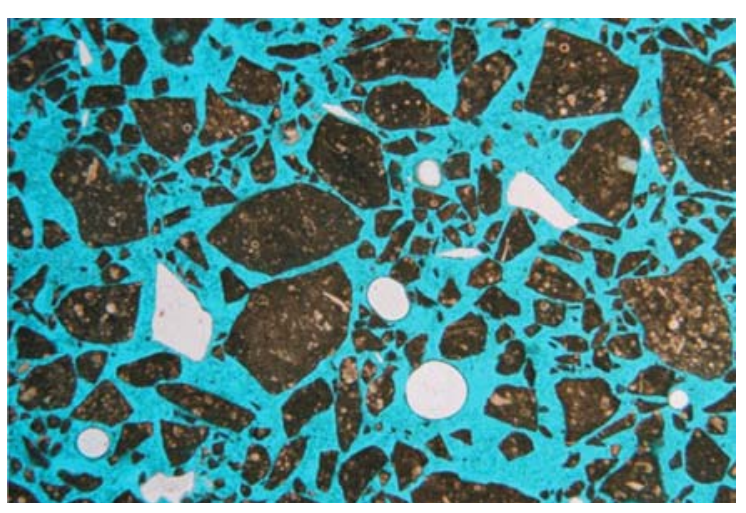

Fig. 5 Optical micrograph of thin section of Ls aggregate, probably crushed chalk, consisting of calcite with scarce angular quartz. $2 \times$ natural light

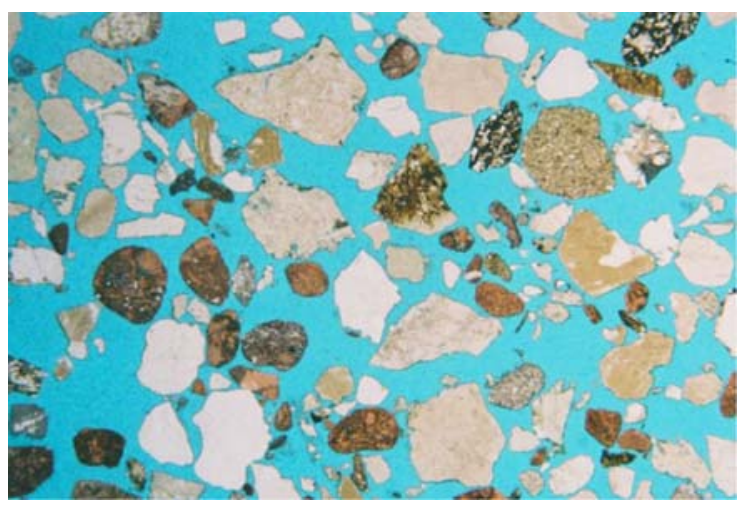

Fig. 6 Optical micrograph of thin section of Mor aggregate including quartz, calcareous limestone and chert, with occasional feldspar, shale, sandstone, granite and metamorphic rock fragments. $2 \times$ polarised light

\subsection{Flexural strength}

The flexural strengths of mortar specimens made with the different aggregates are included in Fig. 11. 


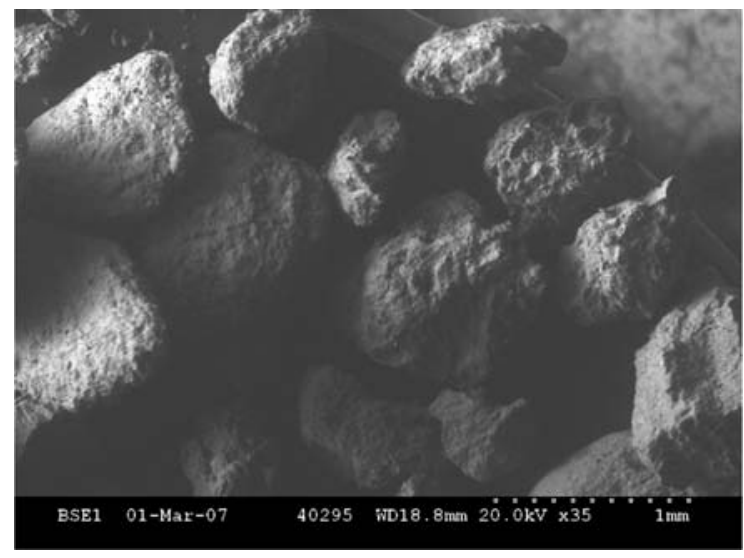

Fig. 7 SEM image of Red 5 aggregate showing very angular grains of medium sphericity

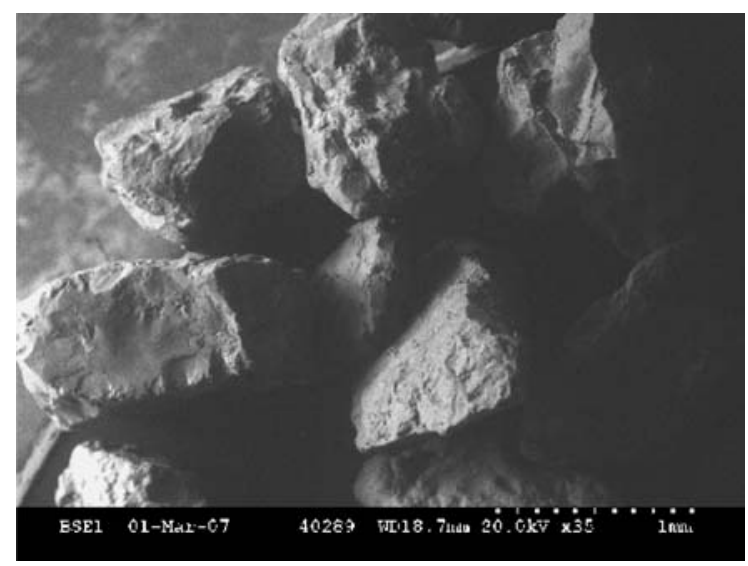

Fig. 8 SEM image of St A aggregate with very angular grains of medium sphericity

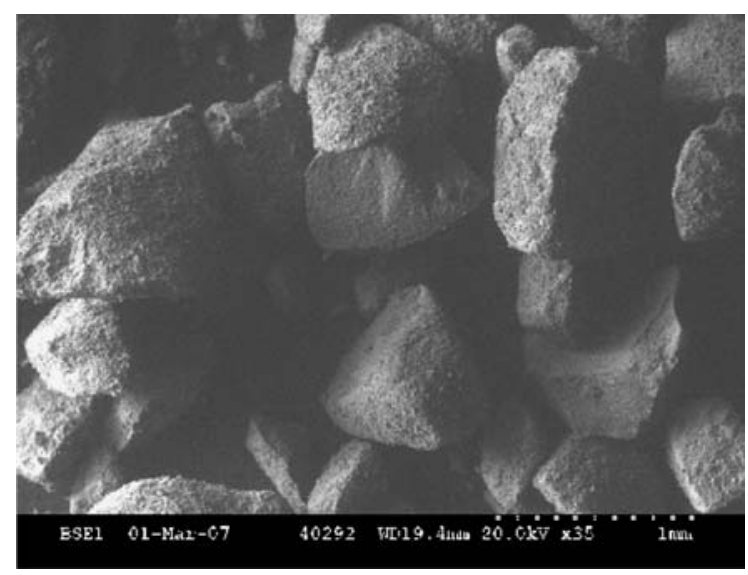

Fig. 9 SEM image of Ls aggregate displaying angular grains of medium sphericity

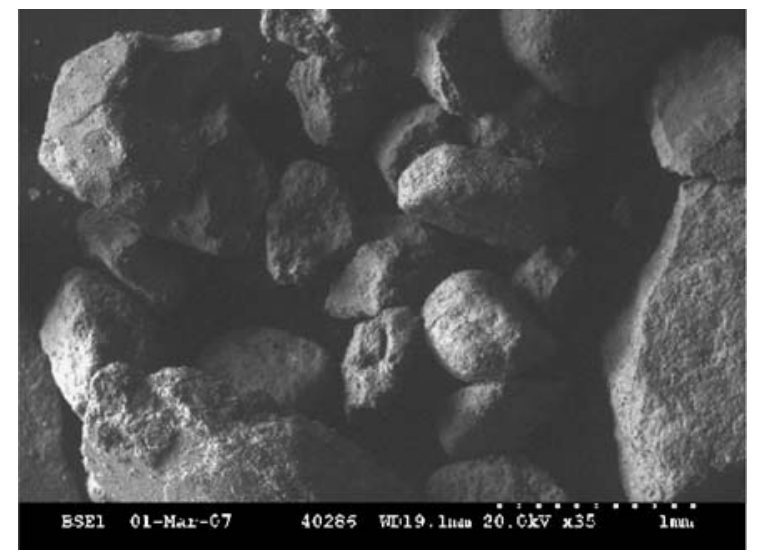

Fig. 10 SEM image of Mor aggregate including both angular and rounded grains of variable sphericity

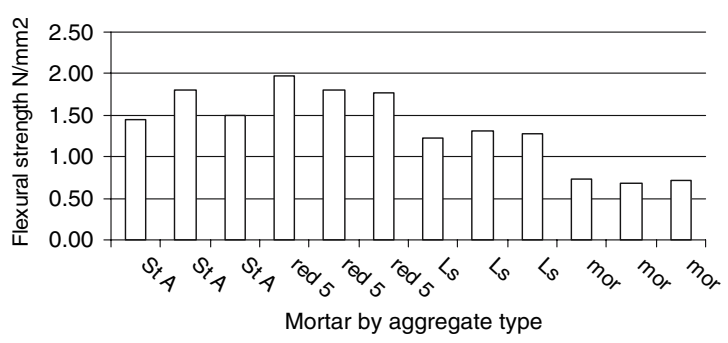

Fig. 11 Flexural strength of mortars by aggregate type

The results suggest that the influence of the aggregate on the mortar's flexural strength is significant. The most angular aggregates (StA and Red5) show the highest flexural strengths. The Red5 aggregate mortars show a $160 \%$ increase in flexural strength when compared to those made with the Mor sand. As aforementioned, the Red 5 aggregate is the sharpest and best graded, this suggests that the flexural strength increases with the aggregate's angularity and that well graded aggregate produces the strongest mortars in bending. The results also evidence that the two sands containing the highest amount of calcite (Ls and Mor) produced the weakest mortars and that the sand with no calcite (Red5) produced the strongest mix. This suggests that, the presence of calcite in the aggregate adversely affects the mortar's flexural strength. However, on assuming this hypothesis, there seems to be a contradiction as mortars made with limestone aggregate (Ls) display higher strengths than those made with granite sand (Mor) which show the lowest strength. However, the 
low strength of the Mor sand mortars is probably due to the high amount fines within the aggregate: the Mor sand possesses the worst grading, including a significant silt and clay fraction (Fig. 1). These fine particles demand additional water during mixing due to their increased specific surface and high water absorption characteristics thus lowering the mechanical strength of the mortar [22-24]. Despite the St A and Limestone sands having a similar grading and a similar particle morphology and average size, the St A sand produced a much stronger mortar in flexural testing. This may be due to the difference in composition, as the St A is highly siliceous and the Limestone sand is a highly calcitic aggregate. According to the results obtained, the flexural strength of a mortar increases as the aggregate's average particle size decreases.

\subsection{Compressive strength}

The compressive strengths of mortar specimens made with the different aggregates are included in Fig. 12.

Like the flexural strength, the influence of the aggregate on the mortar's compressive strength is significant. As it can be seen from Figs. 11 and 12, the compressive strength results are almost proportional to the flexural strength results, with the Red5 sand producing the strongest mortar and the Mor sand producing the weakest. Therefore this indicates that the sharpest, best graded sands of siliceous composition and smallest average particle size produced the strongest mortars while the presence of $\mathrm{CaCO}_{3}$ in the aggregate seems to lower the compressive strength.

\subsection{Porosity and water absorption}

The porosity and water absorption of the mortars made with the different aggregates are included in Fig. 13.

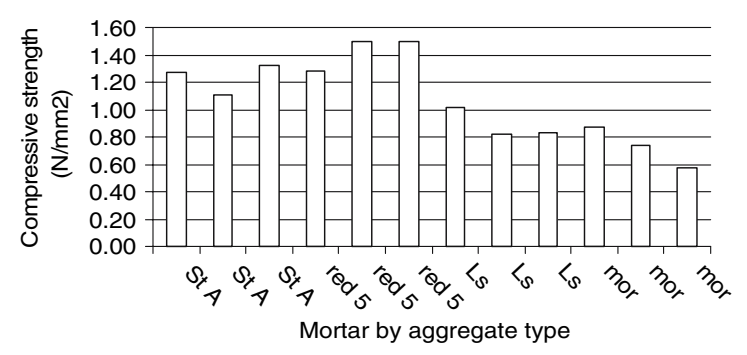

Fig. 12 Compressive strength test results

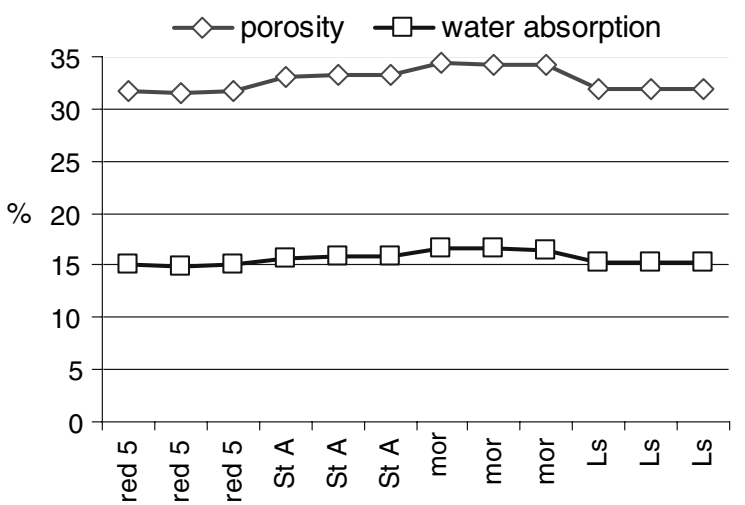

Fig. 13 Porosity and water absorption of the mortars made with different aggregates

Like the flexural and compressive strength results, the water absorption and porosity results are nearly directly proportional to each other, therefore, the conclusions are identical. The lowest average porosity and water absorption are those of the Red5 aggregate (31.61 and $15.02 \%$ respectively) however, the Limestone sand mortars showed similar values of 31.96 and $15.25 \%$, and the StA and Mor mortars $33.23 / 15.77$ and $34.26 / 16.52 \%$ respectively. These results fall approximately within a $1-2 \%$ variation range, suggesting that the influence of the aggregate quality on the moisture transfer properties of the mortar is not as significant as on the mechanical properties. However, it is evident that the Mor aggregate produced the mortar with the highest porosity and water absorption. This is probably due to the fact that Mor sand's contains coarser, more rounded particles than the other aggregates, and also due to the inferior grading of this sand. In contrast, the Red 5 sand, featuring the best grading, sharpest particle size and one of the finest average particle sizes, produced the mortar with the minimum porosity and water absorption. The results also suggest that the calcite content did not affect the mortar's porosity and water absorption.

\subsection{Bulk density}

The Mor sand produced the mortar with the lowest bulk density value $\left(1730.79 \mathrm{Kg} / \mathrm{m}^{3}\right)$ while the Red5 sand produced the mortar with the highest bulk density value $\left(1778.73 \mathrm{Kg} / \mathrm{m}^{3}\right)$ and the limestone and StA sands reached intermediate values of 1776.30 


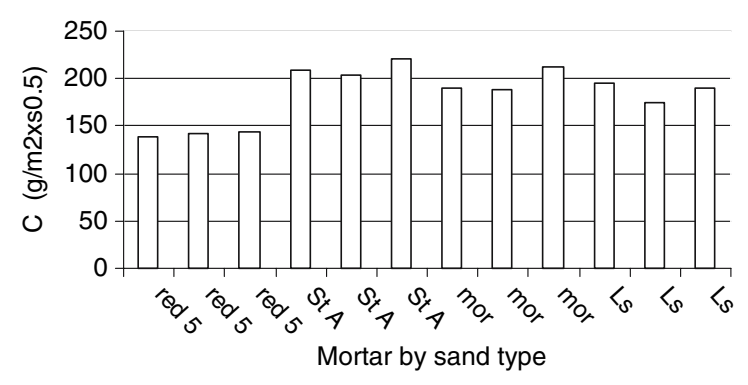

Fig. 14 Capillary suction test results

and $1775.03 \mathrm{Kg} / \mathrm{m}^{3}$ respectively. These close results evidence that the influence of the aggregate's size, shape, grading and calcite content on a mortar's bulk density is not significant. However, the results also indicate that the maximum bulk density is obtained with well graded aggregate including sharp particles of a fine average particle size.

\subsection{Capillary suction}

The capillary suction of the mortars made using the different aggregates is included in Fig. 14.

The St A mortar displayed the highest capillary suction $221.08 \mathrm{~g} / \mathrm{m}^{2} \mathrm{~s}$. sand mortar $\left(212.55 \mathrm{~g} / \mathrm{m}^{2} \mathrm{~s}^{0.5}\right)$. The limestone and Red 5 mortars reached lower values at 187.12 and $141.67 \mathrm{~g} / \mathrm{m}^{2} \mathrm{~s}{ }^{0.5}$ respectively. These indicate that capillary suction is affected by the aggregate quality. For example, there is a $35 \%$ increase in capillary suction between the Red 5 mortar and the St A mortar. The results suggest that a sharp, well graded aggregate of a fine average particle size contributes to minimise capillary suction. However, not all the results are consistent as the mortars made with the St A aggregate, sharpest and better graded than the Mor sand, showed a slightly higher capillary suction than those made with the Mor sand. This may be due to mortar defects such as shrinkage cracks and differential compaction that may cause inaccuracies in capillarity.

\section{Conclusion}

The results of this study suggest that the aggregate quality considerably affects the mechanical properties of mortars and impacts in a lesser extent on the bulk density and moisture transfer properties. Porosity, density and water absorption are more significantly affected by the mortar preparation (i.e. its water content or degree of compaction) than the aggregate quality. While the majority of the conclusions are consistent with previous authors, some of the results conflicted with others. This work concludes that an aggregate with superior grading (containing a wide range of particle sizes) will enhance the mechanical strength and bulk density of a lime mortar simultaneously lowering porosity, water absorption and capillary suction, a conclusion supported by former authors [6, 8, 10-12]. This paper also concludes that angular aggregate will also enhance the mechanical strength and bulk density of a lime mortar lowering its porosity, water absorption and capillary suction. This conclusion also agrees with previous reports by former authors [1-4, 7-9, 11]. In addition, the results suggest that an increase in the aggregate's calcite content tends to lower both flexural and compressive strengths, a finding that conflicted with previous authors $[5,9]$. However, further research is needed in order to make a final statement on this as not only the chemical composition but also the physical properties of the limestone in the aggregate may determine the final mortar properties (e.g. in this research, the limestone sand tested is chalk, a calcitic rock of low mechanical strength). Finally, agreeing with former authors [9, 13], this paper concludes that an aggregate with a small average particle size will also enhance mechanical strength and bulk density of a lime mortar simultaneously lowering its porosity, water absorption and capillary suction. In general, an increase of water absorption, capillary suction, porosity and bulk density is coupled to a raise in mortar permeability which enhances salt, moisture and frost induced damage subsequently undermining mortar durability. Therefore, this paper concludes that angular, wellgraded aggregate with a fine average particle size will produce not only a higher quality but a more durable mortar. However, further research is needed in order to evaluate how aggregate properties such as soundness, porosity and density affect mortar properties.

Acknowledgements Testing was carried out in the Laboratories of the Department of Civil, Structural and Environmental Engineering, Trinity College Dublin. The authors thank Mr. Chris O'Donovan, Chief Technician, for facilitating our laboratory work; Mr. Martin Carney for his help with testing in the Soils Laboratory; Mr. Eoin Dunne for his 
assistance with testing in the Materials Laboratory; Mr Patrick Veale for his chemical analyses and Mr. Dave McAuley for his assistance with the equipment. The authors also thank Mr. Nial Leddy of the Centre for Microscopy and Analysis, TCD, for his assisstance with the SEM/EDX analyses; Ms. Luice Chevert for translating the abstract and St Astier Limes, France, and The Traditional Lime Company, Ireland, for donating materials.

\section{References}

1. Martin R (1976) Palladius Traité D’Agriculture. Livre I. Societé D'Edition 'Les Belles Letres'

2. Eichholz, Pliny the Elder (1962) Natural History. William Heinemann Ltd., Harvard University Press, London, 1962, 2nd edition 1971

3. Hicky Morgan M (1914) Vitruvius: the ten books on architecture. Cambridge: Harvard University Press

4. Plommer F (1973) Vitruvius and later Roman building manuals. Cambridge University Press, London

5. Vicat LJ, A practical and scientific treatise on calcareous Mortars and Cements. John Weale Publ, 1837. Reprinted Donhead 1997

6. Lanas J, Alvarez-Galindo JI (2003) Masonry repair lime based mortars: factors affecting the mechanical behaviour, cem concr res 33(11):1867-1876

7. Holmes S, Wingate M (1997) Building with lime: a practical introduction. ITDG, London

8. Cowper AD Lime and Lime Mortars. Department of Scientific and Industrial Research. Building Research Special Report No. 9. His Majesty's Stationery Office, 1927. Reprinted Shaftesbury, Donhead 1998

9. Lanas J, Perez Bernal JL, Bello MA, Alvarez Galindo JI (2004) Mechanical properties of naturally hydraulic lime based mortars, cem concr res 34:2191-2201

10. The St Astier Company (2001) citing internet sources, '[WWW document] http://www.stastier.com/', accessed 5th November 2005

11. Pavia S, Bolton J (2002) Stone, brick and mortar: historical use, decay and conservation of building materials in Ireland, Wordwell, Co Wicklow
12. Allen G, Allen J, Elton N, Farey M, Holmes S, Livesey P, Radonjicet M (2003) Hydraulic lime mortar for stone, brick and block masonry, Donhead, Shaftesbury

13. Stefanidou M, Papayiannai I (2005) The role of aggregate on the structure and properties of lime mortars, cem concr compos 27

14. BS EN 933-1:1997; 932-2. Tests for geometrical properties of aggregates. Determination of particle size distribution. Sieving method

15. BS EN 459-2:2001 Building lime-Test methods

16. BS EN 196-1:2005 Methods of testing cement-Determination of strength

17. Hanley R (2006) MSc Thesis. Unpublished. Trinity College Dublin

18. RILEM (1980) Essais recommandés pour mesurer l'alteration des pierres et évaluer l'efficacité des méthodes de traitement. Materiaux et Constructions. Bull Rilem 13(75):216-220

19. UNE 67-027-84. Determinacion de la absorcion de agua. Ladrillos

20. BS EN 1925:1999 Natural stone test methods. Determination of water absorption coefficient by capillarity

21. BS 1199 and 1200:1976 Specifications for building sands from natural sources

22. Pavía S (2005) Design of quality, durable mortar for the conservation of historic masonry fabrics. In: Dhir RK, Jones MR, Zheng L (eds) Proceedings of the 6th International Congress: repair and renovation of concrete structures. Global construction: ultimate concrete opportunities. Dundee, Scotland, July 2005. Thomas Telford, London, pp 469-476

23. Pavía S, Fitzgerald B, Howard R (2005) Evaluation of properties of magnesian lime mortar. In: Brebbia CA, Torpiano A (eds) Structural studies, repair and maintenance of heritage architecture IX. Malta, June 2005. Vol 83 WIT transactions on the built environment. WIT Press, pp 375-384

24. Pavía S (2006) Lime mortars for masonry repair: Analytical science and laboratory testing versus practical experience. In: Delgado Rodrigues ans J, Mimoso JM (eds) Preceedings of International Seminar Theory and Practice in Conservation- a tribute to Cesare Brandi. May 2006. Laboratorio Nacional de Engenharia Civil, Lisboa, pp 493-500 